\title{
From Einstein to where?
}

\section{Trevor W. Marshall}

In Search of Reality. By Bernard d'Espagnat.

Springer-Verlag: 1983. Pp.182. Pbk DM 42, \$16.70.

TWENTIETH-century physics has been one long sequence of unresolved questions. Are its elementary objects - light signals, atoms, electrons, quarks - particles or waves? In 1925, the definitive answer was given: "yes"! In so far as one of these objects is a particle, is it in a definite place, or can it be in several places at once? In 1927, Heisenberg plumped for the latter, but also said that an observation put it in one definite place. So what does this imply about reality? Does it mean the elementary objects of physics are not real? Or does it mean the space and time in which they exist is not real?

Physicists, especially Anglo-Saxon ones, have tended to shrug off such "metaphysical" questions, and to listen to philosophers only when they tell us we are right to shrug them off. Thus Wittgenstein ("Whereof we cannot speak, thereof we must be silent"'), or the positivists of the Vienna Circle, are quoted with approval, whilst the realist statements of Karl Popper (in, for example, his Postscript to the Logic of Scientific Discovery) are ignored. But there were always a few physicists, including such substantial thinkers as Planck, Einstein, Ehrenfest, Schrödinger and de Broglie, who stubbornly insisted on posing these questions. With Planck and Einstein it could hardly have been otherwise, since both played crucial roles in establishing, in defence of Boltzmann, the reality of atoms, which involved a decisive rejection of Ernst Mach's positivism.

It is now a whole generation since a physicist or philosopher of such stature addressed these questions seriously. Positivist physicists have retreated into their mathematical formalism, allowing a bowdlerized version of their position to be peddled by out-and-out mystics such as Fritjof Capra (The Tao of Physics) and Gary Zukav (The Dancing Wu Li Masters). Realists have had to make do with ageing survivors of the heroic era, of whom now only Louis de Broglie and Karl Popper remain.

There is, nevertheless, some revival of interest in the ontological questions of physics. This is due in large part to John Bell's rediscovery, in 1965, of Einstein, Podolsky and Rosen's paper of 1935. These authors proposed an experimentally testable property - locality - which they considered the real objects of physics must have. As a result of Bell's efforts, experimental design has now improved to the stage where a test of this property is on the verge of being feasible.

Bernard d'Espagnat's book is a product of this revival. Its original, French version received front-page coverage in Le Monde. While it deserves wider attention from the anglophone world than a brief review in Nature, it may confidently be predicted that it will not make the front pages of our national newspapers. In some ways this is a pity. It could well turn out that Englishspeaking physicists will miss some very fundamental science through their contempt for philosophy. In writing this book d'Espagnat is continuing the efforts of his Conceptual Foundations of Quantum Mechanics, published by Benjamin in 1976, which drew many of the ontological problems to their attention. Though certainly not easy reading, this new book addresses a much broader audience.

The book has one outstanding virtue. It says very clearly why science has a responsibility to concern itself with reality, and, therefore, why positivism, or "the philosophy of experience"' as d'Espagnat calls it, is inadequate:

If the rumor were now to spread that science ultimately misses reality or should not bother with it, then, undoubtedly, the portion of truth that such an assertion contains would at once be simplified and distorted by thousands of commentators ... very happy to be able to justify some superstition or some momentary fashion [p.95].

\section{He can say that again!}

When he comes to offer a realist alternative, d'Espagnat is, however, far less convincing. This is because he is anxious to argue for a particular form of realismnon-physical realism or veiled reality and against physical realism, represented above all by Einstein, but also by today's dominant school in the biological sciences. The latter he obviously considers particularly easy meat for his grinder, for in Chapter 5 he constructs an utterly unfair caricature of the biological scientist operating within a materialist realism which the wise physicist discarded sixty years ago. This is a common enough theme (see for example Freeman Dyson's Disturbing the Universe), but most biologists understand the distinction between life and consciousness quite well, so they are a good deal humbler than this caricature suggests. Indeed, I would say that they are a good deal humbler, regarding the problem of consciousness, than d'Espagnat himself. What they do tend to reject, with good reason, is animism (the idea that every electron has a bit of consciousness), on which d'Espagnat (Chapter 10) seems notably soft.

But, finally, the main target in Bernard d'Espagnat's sights is Albert Einstein and the physical realism which he so firmly advocated. Here also there is a strong element of distortion, but it would be unkind in this case to call it caricature, because I suspect that it has been done unwittingly. The "realist" analysis of a two-body decay process, which d'Espagnat gives in Chapter 4 and Appendix I, limits very narrowly the range of models of a local realist type. It is a comparatively easy matter to construct an experiment which refutes models from within this range. To claim, as does d'Espagnat repeatedly, that any philosophical position, let alone that of Einstein, has been thereby rendered invalid, is a gross intellectual indulgence. The point d'Espagnat has overlooked is that, if we leave the narrow domain of determinist theories, there is no difficulty at all in explaining the data obtained in the experiments so far performed. Needless to say, such experiments use real detectors, with approximately $20 \%$ efficiency, and not the ideal ones, with $100 \%$ efficiency, described by d'Espagnat.

I would conclude that Bernard d'Espagnat has made out a convincing case for going out in search of reality. But he has probably not found it because he refused to look in some of the places where it is most likely to be.

Trevor W. Marshall is a Lecturer in Mathema tics at the University of Manchester.

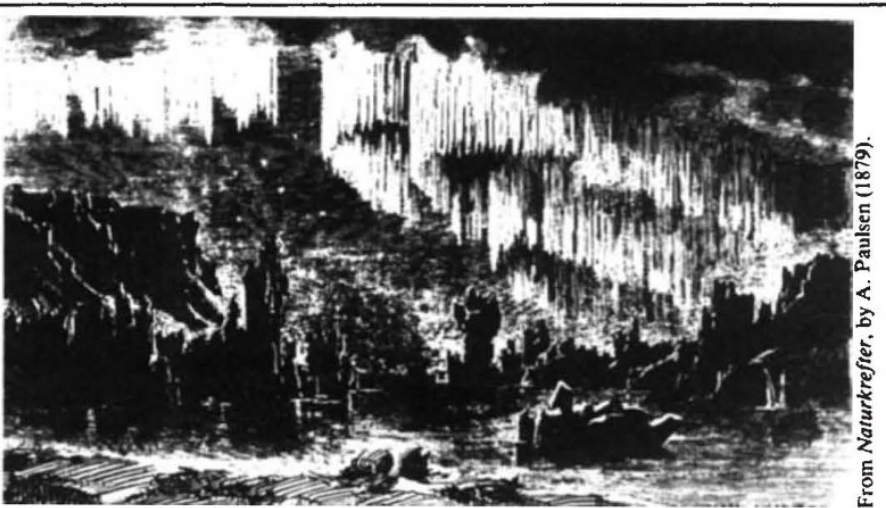

Heavenly light - the picture is reproduced from A. Brekke and A. Egeland's The Northern Light, a well-illustrated, large-format book which explores the art and science stimulated by the aurora borealis. Publisher is Springer-Verlag, price is DM108, $\$ 42.90$. 